\title{
Propiedades sociométricas del cuestionario de arraigo familiar en supuestos de custodia compartida disputada
}

\section{Raúl Ruiz-Callado}

Departamento de Sociología I, Universidad de Alicante raulruiz@ua.es

\author{
Rafael Alcázar \\ Departamento de Sociología I, Universidad de Alicante \\ rafael.alcazar@ua.es
}

\begin{abstract}
Artikulu honetan familia-epaitegietan dibortziatzen ari diren eta zaintza erabakitzear duten gurasoen seme-alaba adingabekoen sustraitze familiarra neurtzeko kasuetarako eskala baliagarri eta fidagarri bat osatzen inguruko ikerketa baten berri ematen da. Hori lortzeko, eskalaren ezaugarri soziometrikoak aztertu dira eta zaintzaren aldaketa moduaren aldagaiarekin erlazionatu dira. Bertan aurkeztutako lan-hipotesiaren arabera, zaintza partekatuko erregimena duten adingabekoen kasuan tankerako sustraitze familiarra gertatzen omen da aitaren edo amaren etxebizitzetan bizi direnen artean.
\end{abstract}

\section{GAKO-HITZAK:}

Zaintza partekatua, sustraitze familiarra, dibortzia, ikerketa sozialeko teknikak, adingabeak.
Este artículo recoge una investigación realizada con el objetivo de construir una escala válida y confiable que mida el arraigo familiar de los menores cuyos padres se encuentran en trámites de divorcio cuando la custodia compartida es una cuestión disputada en el juzgado de familia. Para ello se han estudiado las propiedades sociométricas de la escala y se han relacionado sus dimensiones con la variable tipo de custodia. La hipótesis de trabajo que se plantea es que los menores en custodia compartida encuentran puntuaciones de arraigo familiar similares en el domicilio paterno y materno.

\section{Palabras Clave:}

Custodia compartida, arraigo familiar, divorcio, técnicas de investigación social, menores. 


\section{Introducción}

En los últimos años estamos asistiendo a una restructuración del modelo de familia, directamente relacionada con la evolución y las transformaciones propias de la sociedad. Se han ido produciendo una serie de cambios legislativos en materia de divorcio. Así, la Ley 15/2005 eliminó el requisito de la separación judicial previa al divorcio e introdujo, por primera vez, la posibilidad de acordar la custodia compartida de los menores. Antes de esta ley, dicha posibilidad no estaba prevista legalmente (Alascio, 2011).

Posteriormente, entre los años 2005 y 2010, el modo de acceso al régimen de custodia compartida exigía el acuerdo entre las partes. Por este motivo, su tramitación se realizaba casi exclusivamente por la vía del mutuo acuerdo y no entraba dentro de la custodia disputada. En consecuencia, las resoluciones judiciales reflejaban el acuerdo entre las partes, pero el tribunal no se pronunciaba sobre la procedencia o viabilidad del régimen de custodia compartida.

Unos años después, entre los años 2011 y 2012, se llevaron a cabo reformas legislativas ${ }^{1}$ por parte de algunas comunidades autónomas con competencia en la regulación de las relaciones paterno-filiales, con dos denominadores comunes: el cambio en la terminología que regula las relaciones paternofiliales (desaparición del término régimen de visitas) y la flexibilización del acceso a un modelo de custodia compartida tras la ruptura familiar, ya que no se necesita el acuerdo entre las partes para su acceso.

Los cambios legislativos referidos a los que asistimos son un reflejo de un cambio social que afecta a la estructura, dinámica y composición de las familias. En este sentido, según el Instituto Nacional de Estadística (INE, 2010-2017), el porcentaje de resoluciones judiciales favorables a un modelo de custodia única materna pasó de un 83,2 \% en el año 2010 a un $66,2 \%$ en el año 2017 , mientras que la modalidad de custodia compartida ha aumentado del $10,5 \%$ en el año 2010 al $28,3 \%$ en 2017 , por lo que se puede afirmar que se asiste a un proceso de cambio progresivo hacia un modelo de custodia compartida incluso en casos en que se produce una conflictividad entre los cónyuges.

El auge de la custodia compartida responde al cambio social que se ha producido en el terreno de la igualdad entre hombres y mujeres. El acceso de las mujeres al mercado laboral (Jurado, 2008 y Cea D`Ancona, 2007) y el ejercicio de la coparentalidad,

${ }^{1}$ Legislación española sobre custodia compartida: Código Civil modificado por Ley 15/2005. El Gobierno está preparando una modificación sobre la materia. Decreto Legislativo 1/2011, de 22 de marzo de Gobierno de Aragón. Código Civil de Cataluña, Libro II, aprobado por Ley 25/2010 de 29 de julio. Ley Foral 3/2011, de 17 de marzo, sobre custodia de los hijos en los casos de ruptura de la convivencia de los padres de Navarra. entendido no tanto como una fórmula legal, sino como una filosofía basada en la premisa de que los padres y las madres cooperan y comparten autoridad y responsabilidad parental tras el divorcio (Saposnek,1991).

\section{Custodia compartida y cambio social}

La explicación de estos cambios ha sido debatida por diferentes autores y ha recibido distintas denominaciones, por ejemplo: "segunda modernidad” (Beck y Beck-Gernsheim, 2003), “modernidad líquida" (Bauman, 2012), o "sociedad red" (Castells, 2006).

Desde esta perspectiva, el estudio de la custodia compartida puede ser considerado como una expresión de este cambio social. En él se refleja de un modo claro el tránsito de un modelo de sociedad a otro. Ello supone la crisis del modelo de familia patriarcal (Castells, 2003) que marca el paso a otro modelo de familia negociadora donde los roles de género no constituyen una relación de desigualdad ente padres y madres (Meil, 2006). El rasgo más característico de este tipo de familia negociadora respecto a los padres es la pérdida de legitimidad de los roles en función del género, así como el desgaste de la ideología patriarcal. Dicho cambio exige un reparto de las responsabilidades entre los progenitores y requiere de una mayor negociación entre ellos. En este contexto de negociabilidad de las relaciones y de los roles familiares, emerge un nuevo pacto conyugal donde se desarrolla el nuevo modelo de familia.

Este nuevo modelo de familia se caracteriza por la negociación de los roles de género entre los cónyuges y también por el consenso de las costumbres y normas que regulan su convivencia. Así, la coparentalidad emerge como concepto vinculado a la custodia compartida. Sin embargo, el término custodia compartida es un concepto abstracto y poliédrico (Ibáñez Valverde, 2004), con significados diferentes según quién, dónde o con qué intención se utilice. Este concepto se ha desarrollado a lo largo de las últimas décadas y presenta una fuerte controversia por cuanto que tiene tanto encendidos defensores como detractores quienes, curiosamente, utilizan a menudo argumentos similares, a contrario sensu, para justificar sus posiciones (Cea d'Ancona, 2007).

En cualquier caso, para el estudio de la custodia compartida es preciso hablar y conocer los criterios que tienen en cuenta los tribunales en las decisiones sobre ella. Cuando hablamos de criterios, se hace referencia a aquello que se considera importante cuando se valora una situación en la que debe recomendarse un sistema de custodia (Arch, 2008; Ruiz-Callado y Alcázar, 2017). El establecimiento de estos criterios de atribución de custodia se ha ido conformando bajo las diferentes influencias socioculturales de cada época en relación con la 
familia. Estos criterios no han permanecido inmóviles con el paso del tiempo y no han sido ajenos a los cambios sociales (Ramírez González, 2003). Por ello, el estudio de dichos criterios tiene interés sociológico, ya que trata de mostrar cómo la vida personal y las biografías individuales de las familias en proceso de ruptura están íntimamente conectadas con los acontecimientos históricos y los procesos estructurales que se viven en un momento concreto (Bauman, 2015).

Algunos autores, como Rodríguez Domínguez et al. (2015), Solsona et al. (2017), Suso et al. (2012) y Viñes (2012), han realizado un estudio pormenorizado de los criterios que los tribunales españoles tienden a utilizar para otorgar la custodia compartida cuando esta es una cuestión disputada en el juicio. En estos casos es el tribunal quien decide sobre ella y la resolución judicial no es el resultado del consenso entre las partes.

Por todo esto resulta pertinente analizar los criterios comunes en todas las leyes sobre custodia compartida ${ }^{1}$, y estos son: la vinculación afectiva entre hijos y padres, la capacidad de los padres, el arraigo familiar y social de los menores, la figura de cuidador primario y posibilidad de conciliación de la vida laboral y familiar, la audiencia o deseo de los menores, el grado de comunicación de los padres y el criterio de continuidad u organización posruptura (Solsona et al. 2017).

Todos estos criterios son importantes en la atribución de la custodia compartida por el tribunal. Sin embargo, en esta investigación nos centramos en el arraigo familiar como criterio de atribución de la custodia compartida dado su interés sociológico. Etimológicamente, el término arraigo se refiere a la acción de afincarse de modo permanente, o echar raíces. El concepto arraigo social es utilizado ampliamente en la disciplina del derecho y también en sociología.

En el contexto jurídico, el término arraigo social ha sido empleado en el ámbito de extranjería y también en el contexto penal. Así, la Ley Orgánica 4/2000, de 11 de enero, sobre Derechos y Libertades de los Extranjeros en España y su Integración Social (artículo 31.3) se refiere a una autorización administrativa de residencia temporal por circunstancias excepcionales que se podrá conceder a ciudadanos extranjeros que se hallen en España $y$, o bien tengan vínculos familiares en España o estén integrados socialmente. De este modo, aquella persona inmigrante que acredite una situación de arraigo social puede acceder a permiso de residencia y de trabajo.

En el ámbito penal también se utiliza el término arraigo. Así se refiere, en base al artículo 502 y 503 de Real Decreto de 14 de septiembre de 1882 , que aprueba la Ley de Enjuiciamiento Criminal, a los factores a tener en cuenta por parte del tribunal en la adopción de la prisión provisional. Una persona en prisión provisional puede ser trasladada a otro centro penitenciario cuando se acredita una situación de arraigo social.

Las situaciones particulares de arraigo social en materia de legislación penitenciaria o de extranjería exigen el cumplimiento de unos requisitos legales y técnicos que son evaluados por expertos provenientes del trabajo social y de la sociología, de ahí la relación intrínseca entre la sociología y el trabajo social en la valoración del arraigo social.

Para la valoración del arraigo social, retomamos desde las ciencias sociales el término capital social, noción que guarda una estrecha relación con el concepto de arraigo social y que se refiere a los lazos del individuo con su contexto social más próximo. Por esto, las familias son una fuente de capital social, ya que en su seno se producen las conexiones entre individuos que a menudo aportan apoyo instrumental, informativo y emocional a las personas que la conforman. La importancia de las relaciones familiares como capital social ha sido subrayada por diferentes autores (Coleman, 1988; Furstenberg, 2005; Furstenberg y Hughes, 1995).

Putnam (2000) propone una definición de capital social vínculo (bonding social capital) y capital social puente o conectivo (bridging social capital). El capital social vínculo está formado por los lazos fuertes o relaciones de confianza, que comprende a la familia, amigos y vecindario, por el cual se refuerzan los lazos entre grupos homogéneos a partir de identidades excluyentes. Los lazos y los mecanismos de solidaridad son fuertes para los que comparten las características del grupo de referencia, pero, a la vez, muy excluyentes para los ajenos a ella.

El capital social puente (bridging social capital) es una alternativa al capital social vínculo. Mientras que el capital social vínculo se basa en las relaciones de individuos o grupos similares dentro del mismo grupo social, el capital social puente se refiere a las distintas conexiones entre grupos y comunidades diferentes. El capital social conectivo está formado por vínculos débiles o puntuales donde se recogen las relaciones entre grupos disímiles, o servicios formales (Burt, 1995; Granovetter, 1973). En un contexto familiar de divorcio, el sistema de conexiones afectivas entre los miembros de la familia se ve alterado, especialmente para los hijos e hijas. Por esto, el capital social vínculo pierde importancia y el capital social puente cobra fuerza y aparece como un desafío, como una amenaza y como una oportunidad de desarrollo de la autonomía personal. Este es el papel que desempeñan las nuevas familias reconstituidas, lo que implica una redefinición de los vínculos familiares con consecuencias en la producción y la disponibilidad de capital social para todos los miembros de la familia, en especial los hijos (Widmer et al., 2013).

En este artículo nos referimos al arraigo social en cuanto a que las familias en proceso de divorcio 
$y$, en consecuencia, en proceso de cambio y reestructuración de sus relaciones, ven afectados sus capitales puente y vínculo, no solo en su núcleo familiar más próximo, sino también con otros miembros de la familia extensa y reconstituida. El estudio que aquí se presenta se centra en el criterio del arraigo familiar como factor relevante en la evaluación de la custodia compartida. El objetivo principal se orienta a la elaboración de un cuestionario que permita la evaluación y la medición del arraigo familiar de los menores en casos de custodia compartida. Se estudian las propiedades sociométricas de la escala y se relacionarán sus dimensiones con la variable tipo de custodia.

La hipótesis de trabajo que se plantea es que los menores en custodia compartida encuentran puntuaciones de arraigo familiar similares en el domicilio paterno y materno. Por el contrario, las puntuaciones de arraigo familiar en custodia única son mayores en el domicilio materno. Por otra parte, las valoraciones de los menores respecto a la presencia de la familia extensa y familia reconstituida son diferentes en custodia única y en custodia compartida.

\section{Método}

\subsection{Diseño y ámbito}

Se trata de un estudio descriptivo y transversal, realizado en los juzgados de familia de Alicante, Comunidad Valenciana, España. La recogida de información se realizó durante el periodo comprendido entre el 1 de enero de 2013 hasta el 31 de diciembre de 2017 .

En este estudio han participado 115 menores cuyos progenitores se encontraban divorciados y la custodia compartida era una cuestión disputada en el tribunal. La participación fue voluntaria y el único criterio de inclusión que se contempló fue el hecho de que la familia se encontrase en trámite de divorcio o separación y tener hijos o hijas de esta pareja. La edad de los menores oscilaba entre los seis y los diecisiete años, que es la edad en la que los menores son entrevistados por los técnicos en los tribunales. El $52,2 \%$ eran chicos y el $47,8 \%$ chicas, y su media de edad era de once años

\subsection{Validez de contenido}

En este apartado se realizó una revisión de la documentación encontrada y seleccionada para el estudio de la variable "arraigo familiar" en las bases de datos de Proquest, Google Scholar y Dialnet, atendiendo por un lado a su relevancia en nuestro campo y, por otro, a la fecha de estudio (se seleccionaron preferentemente los elaborados entre los últimos cinco años). Por otro lado, se llevó a cabo una aproximación cualitativa al concepto de arraigo familiar en el contexto judicial gestionando un comité de expertos conformado por dos juezas de familia, dos psicólogas, dos trabajadoras sociales y un sociólogo. Se realizó un grupo de discusión con el objeto de llegar a un consenso intersubjetivo en lo referente a la definición de los elementos relevantes en la evaluación del término arraigo familiar.

Una vez examinada la bibliografía consultada y, alcanzado el consenso en el grupo de discusión referente a la definición del constructo arraigo social y familiar, se llega a las siguientes conclusiones: el arraigo social se refiere principalmente a que la custodia compartida exige que el menor tenga uno o dos domicilios en una misma localidad. No cabe custodia compartida en localidades muy alejadas entre sí. Puede haber una cierta distancia entre localidades, incluso puede existir un cambio en las rutinas que conforman la vida cotidiana del menor, pero en ningún caso comprometer su adaptación escolar.

El arraigo familiar remite al vínculo afectivo con los padres, la familia extensa y las familias reconstituidas y sus preferencias por residir en ambos domicilios. Esta investigación se centra en el concepto y medición del arraigo familiar.

\subsection{Elaboración del cuestionario de arraigo familiar (CAF) y procedimiento}

Para la elaboración del cuestionario de arraigo familiar se utilizó inicialmente una base compuesta por veinte ítems, basados en diversos aspectos considerados relevantes en la literatura sobre las relaciones familiares posdivorcio, y que se refieren a la valoración que los menores hacen del domicilio paterno y materno, su relación con la familia extensa y las relaciones con la nueva familia reconstituida (Ruiz-Rodríguez, 2013; Gómez y Soto, 2015).

Como formato de respuesta se utilizó una escala Likert con cuatro alternativas: Nunca (o), A veces (1), Muchas veces (2), y Siempre (3). Se evitó la alternativa neutra: ni de acuerdo ni en desacuerdo, o algunas veces, con el fin de evitar posicionamientos poco claros, especialmente en contextos de divorcio en los que los menores pueden encontrarse en situación de conflicto de lealtades y optar por esta alternativa de respuesta más neutral (Ramírez González, 2003).

El cuestionario fue aplicado a una muestra preliminar de menores cuyos padres se encontraban en trámites de divorcio para comprobar el funcionamiento de los ítems. Se eliminaron aquellos que resultaron ambiguos, redundantes o con una baja frecuencia de respuesta. Asimismo, se realizó un análisis factorial mediante el cual se descartaron los ítems que pesaban de manera similar en todos los factores, o cuyo autovalor fuera menor de 0,30. Por último, se analizó exploratoriamente la fiabilidad del instrumento y se descartaron aquellos ítems que al ser eliminados producían un aumento de la 
consistencia interna. De esta manera el cuestionario de arraigo familiar quedó conformado por ocho ítems (véase el Anexo l).

Examinada la fiabilidad y realizado el análisis factorial de la escala, se procedió a obtener una nueva variable, índice global de arraigo familiar y se relacionó con la variable tipo de custodia, cuya alternativa de respuesta dicotómica fue custodia compartida o custodia única.

La Consellería de Justicia de la Comunidad Valenciana facilitó el contacto con los profesionales adscritos a los equipos técnicos evaluadores de la custodia compartida en los tribunales. En el cuestionario se preguntó al menor por el modo en que se sentía en el entorno familiar paterno y materno y también se le preguntó por las personas que conformaban su nueva estructura familiar, incluyendo los miembros de las familias reconstituidas, cuando las hubiera.

Las entrevistas con los menores fueron realizadas por el equipo técnico adscrito al juzgado, conformado por psicólogo/a y trabajador/a social, encargados de la evaluación de la custodia. Al equipo se le facilitó el cuestionario sobre arraigo social que fue pasado a los menores objeto de evaluación. Se descartaron aquellos cuestionarios que a juicio de los profesionales no resultaban válidos, porque la opinión de los menores aparecía distorsionada por el conflicto familiar, o cuando los menores no eran capaces de expresar con palabras lo que sentían.

\section{Resultados}

\subsection{Estructura factorial del cuestionario de arraigo familiar (CAF) en casos de custodia disputada.}

En primer lugar, a fin de comprobar la adecuación muestral para un análisis factorial, se calcularon el índice de Kaiser-Meyer-Olkin (KMO) y el test de esfericidad de Bartlett. El índice KMO mostró un valor de 0,8 y el test de Bartlett resultó estadísticamente significativo, $\chi 2(78)=111,654$ p < 0,000. Así pues, se realizó un análisis de componentes principales con rotación Varimax. Siguiendo el criterio de extracción de factores de Kaiser, se obtuvieron cuatro factores con valores propios iguales o superiores a la unidad. Estos factores, cuyos autovalores fueron 5,3, 2,1, 1,5 y 1,1 explicaban el 70,4\% de la varianza total.

En la Tabla 1 se expone las comunalidades que representan la varianza de cada variable explicada por los factores. Se puede observar que las variables quedan bien explicadas por el modelo compuesto por cuatro factores al ser mayores del $5 \%$. Del mismo modo, en la Tabla 2 se representa la matriz de componentes rotados. El primer componente, que reúne los ítems del 1 al 4, se refiere a las valoraciones que los hijos/as hacen del domicilio paterno. El segundo componente se refiere a las valoraciones que hacen los menores del domicilio materno. El tercer factor reúne las variables referidas a la familia extensa y el cuarto aglutina a los miembros de las familias reconstituidas.

Tabla 1. Comunalidades de las variables

\begin{tabular}{|l|c|c|}
\cline { 2 - 3 } \multicolumn{1}{l|}{} & Inicial & Extracción \\
\hline Padre & 1,000 & 0,625 \\
\hline Familia reconstituida paterna & 1,000 & 0,689 \\
\hline Familia reconstituida materna & 1,000 & 0,551 \\
\hline Familia extensa paterna & 1,000 & 0,629 \\
\hline Familia extensa materna & 1,000 & 0,763 \\
\hline Me gusta estar en esta casa (madre) & 1,000 & 0,391 \\
\hline $\begin{array}{l}\text { Aquí tengo mi propia habitación y mis cosas } \\
\text { (madre) }\end{array}$ & 1,000 & 0,794 \\
\hline Se come bien en esta casa (madre) & 1,000 & 0,750 \\
\hline Me siento bien en esta casa (madre) & 1,000 & 0,817 \\
\hline Me gusta estar en esta casa (padre) & 1,000 & 0,836 \\
\hline Se come bien en esta casa (padre) & 1,000 & 0,744 \\
\hline Me siento bien en esta casa (padre) & 1,000 & 0,890 \\
\hline $\begin{array}{l}\text { Aquí tengo mi propia habitación y mis cosas } \\
\text { (padre) }\end{array}$ & 1,000 & 0,674 \\
\hline
\end{tabular}

Fuente: elaboración propia a partir de los datos obtenidos en los juzgados de familia de Alicante, 2013-2017.

Tabla 2. Matriz de componentes rotados

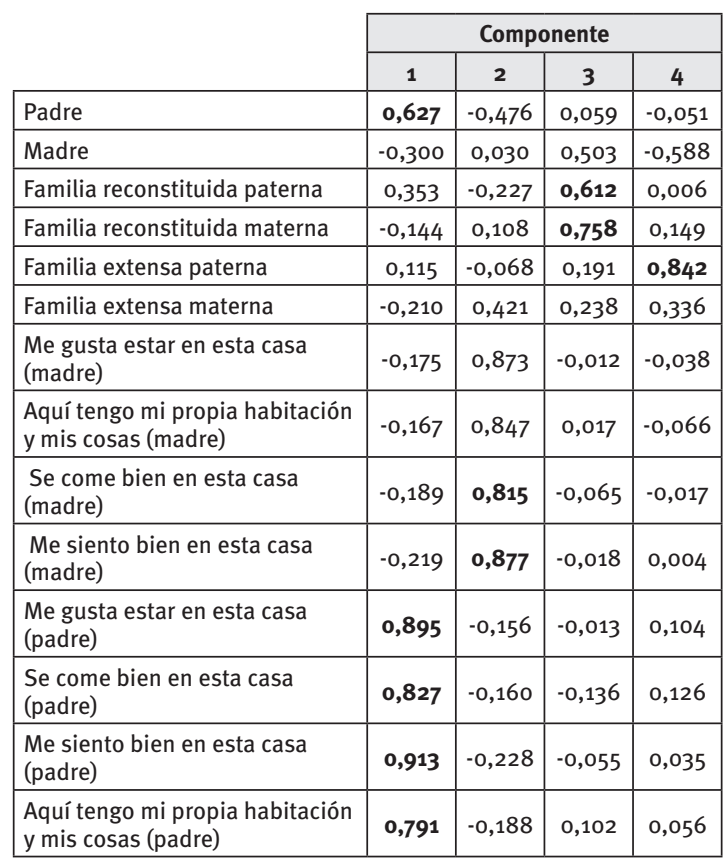

Fuente: elaboración propia a partir de los datos obtenidos en los juzgados de familia de Alicante, 2013-2017.

\subsection{Fiabilidad del cuestionario de arraigo familiar (CAF)}

Como medida de fiabilidad se evaluó la consistencia interna del cuestionario mediante el índice $\alpha$ de Cronbach. Obtuvimos un coeficiente $\alpha$ de 0,742 que es considerado buen indicador de la consistencia interna de la escala (Cea D’Ancona, 1999). No obstante, en la Tabla 3 pueden observarse las 
saturaciones y las correlaciones total-elemento correspondientes a cada uno de los ítems que componen la escala. Esta correlación indica la correlación lineal entre el ítem y la puntuación total (sin considerar el ítem que se está evaluando), señalando la magnitud y la dirección de esta relación. Se observa que algunos coefiecientes ítem-total arrojan valores menores a 0,35. Sin embargo, no se desechan porque su contribución al incremento del coeficiente alfa de Cronbach no resulta significativo. Así, por ejemplo, el ítem 1, Me gusta estar en casa de mi madre adopta un valor 0,131, pero su eliminación apenas impacta en el índice alfa de Cronbach, que aumenta a 0,78 . Además, se observa que todos los ítems menores de 0,35 reúnen variables referidas al entorno familiar de la madre, lo que sugiere que la escala es consistente por arrojar un alpha de Cronbach de 0,742 , pero no es unidimensional, ya que en la escala concurren variables relacionadas con el entorno del padre y variables relacionadas con el entorno de la madre.

\subsection{Análisis bivariable}

En la Tabla 4 se muestran los coeficientes de prueba $T$ de Student que contrasta los valores medios en las muestras de custodia única y custodia compartida obtenidos para las variables: bienestar en vivienda del padre, bienestar en vivienda de la madre, relación con padres, relación con hermanos, relación con familia extensa y relación con familia reconstituida. Estas variables se han construido a partir de los valores medios obtenidos en los factores extraídos en el análisis de componentes principales.

Como se puede observar, las variables bienestar en casa del padre, nivel de satisfacción con familia extensa y con familia reconstituida están relacionados con la variable tipo de custodia. En estos casos se rechaza la hipótesis nula relativa a la igualdad de medias en ambas muestras, por lo que se evidencia que el grado de bienestar que los menores refieren en el domicilio de su padre son mayores en custodia compartida que en custodia única. Por otra parte, el grado de participación de los miembros de la familia extensa paterna y familias reconstituidas en la vida de los menores resulta más satisfactorio para éstos en custodia compartida que en custodia única. Estas diferencias no afectan de forma estadísticamente significativa en el grado de relación que los menores tienen con sus abuelos maternos, las parejas e hijos/as de sus madres, ni tampoco al nivel de satisfacción general en el domicilio de sus madres.

Tabla 3. Estadísticos total-elemento

\begin{tabular}{|c|c|c|c|c|}
\hline & $\begin{array}{l}\text { Media de escala si } \\
\text { el elemento se ha } \\
\text { suprimido }\end{array}$ & $\begin{array}{l}\text { Varianza de escala } \\
\text { si el elemento se ha } \\
\text { suprimido }\end{array}$ & $\begin{array}{l}\text { Correlación total de } \\
\text { elementos corregida }\end{array}$ & $\begin{array}{l}\text { Alfa de Cronbach si } \\
\text { el elemento se ha } \\
\text { suprimido }\end{array}$ \\
\hline Me gusta estar en esta casa (madre) & 33,115 & 30,50 & 0,131 & 0,788 \\
\hline $\begin{array}{l}\text { Aquí tengo mi propia habitación y mis } \\
\text { cosas (madre) }\end{array}$ & 33,115 & 31,17 & 0,076 & 0,788 \\
\hline Se come bien en esta casa (madre) & 33,192 & 31,14 & 0,073 & 0,789 \\
\hline Me siento bien en esta casa (madre) & 33,038 & 31,26 & 0,072 & 0,788 \\
\hline Índice Madre & 33,884 & 30,75 & 0,057 & 0,796 \\
\hline Índice Familia Reconstituida (madres) & 33,653 & 28,80 & 0,228 & 0,786 \\
\hline Índice Familia Extensa (madres) & 33,000 & 30,87 & 0,186 & 0,783 \\
\hline Índice Hermanos/as & 33,115 & 32,00 & $-0,078$ & 0,796 \\
\hline Me gusta estar en esta casa (padre) & 33,653 & 23,64 & 0,750 & 0,730 \\
\hline $\begin{array}{l}\text { Aquí tengo mi propia habitación y mis } \\
\text { cosas (padre) }\end{array}$ & 33,500 & 22,667 & 0,823 & 0,720 \\
\hline Se come bien en esta casa (padre) & 33,346 & 26,058 & 0,557 & 0,754 \\
\hline Me siento bien en esta casa (padre) & 33,346 & 25,141 & 0,671 & 0,742 \\
\hline Índice Fam. Reconstituida (padres) & 33,730 & 25,526 & 0,744 & 0,739 \\
\hline Índice Fam. Extensa (padres) & 33,576 & 27,744 & 0,370 & 0,772 \\
\hline Indice Padre & 34,038 & 24,853 & 0,660 & 0,742 \\
\hline
\end{tabular}

Fuente: elaboración propia a partir de los datos obtenidos en los juzgados de familia de Alicante, 2013-2017. 
Tabla 4. Tabla resumen de los contrastes de hipótesis según tipo de custodia*

\begin{tabular}{|c|c|c|c|c|c|c|c|c|}
\hline Índices & Tipo de custodia & $\mathbf{N}$ & Media & Sigma & $\mathbf{T}$ & GI & Sigma & Decisión \\
\hline \multirow{2}{*}{ Fam. recons. Padre } & Única & 36 & 1,1 & 1,11 & \multirow{2}{*}{$-2,72$} & \multirow{2}{*}{54} & \multirow{2}{*}{0,009} & \multirow{2}{*}{ RECHAZO } \\
\hline & Compartida & 20 & 2,0 & 1,14 & & & & \\
\hline \multirow{2}{*}{ Fam. recons. Madre } & Única & 38 & 1,8 & 1,11 & \multirow{2}{*}{$-1,27$} & \multirow{2}{*}{52} & \multirow{2}{*}{0,20} & \multirow{2}{*}{ ACEPTACIÓN } \\
\hline & Compartida & 16 & 2,3 & 1,07 & & & & \\
\hline \multirow{2}{*}{$\begin{array}{l}\text { Familia extensa } \\
\text { padre }\end{array}$} & Única & 83 & 1,4 & 0,954 & \multirow{2}{*}{$-3,06$} & \multirow{2}{*}{111} & \multirow{2}{*}{0,003} & \multirow{2}{*}{ RECHAZO } \\
\hline & Compartida & 30 & 2,0 & 0,785 & & & & \\
\hline \multirow{2}{*}{$\begin{array}{l}\text { Familia extensa } \\
\text { madre }\end{array}$} & Única & 84 & 2,2 & 0,812 & \multirow{2}{*}{$-0,43$} & \multirow{2}{*}{112} & \multirow{2}{*}{0,966} & \multirow{2}{*}{ ACEPTACIÓN } \\
\hline & Compartida & 30 & 2,2 & 0,679 & & & & \\
\hline \multirow{2}{*}{ Hermanos } & Única & 69 & 2,6 & 0,610 & \multirow{2}{*}{0,1} & \multirow{2}{*}{90} & \multirow{2}{*}{0,92} & \multirow{2}{*}{ ACEPTACIÓN } \\
\hline & Compartida & 23 & 2,6 & 0,573 & & & & \\
\hline \multirow{2}{*}{ Padre } & Única & 82 & 1,7 & 0,905 & \multirow{2}{*}{$-2,61$} & \multirow{2}{*}{109} & \multirow{2}{*}{0,010} & \multirow{2}{*}{ RECHAZO } \\
\hline & Compartida & 29 & 2,2 & 0,792 & & & & \\
\hline \multirow{2}{*}{ Madre } & Única & 84 & 2,4 & 0,686 & \multirow{2}{*}{,- 037} & \multirow{2}{*}{112} & \multirow{2}{*}{0,7} & \multirow{2}{*}{ ACEPTACIÓN } \\
\hline & Compartida & 30 & 2,3 & 0,529 & & & & \\
\hline & Única & 85 & 2,4 & 0,840 & & & & \\
\hline Casd made & Compartida & 30 & 2,5 & 0,589 & $-0,42$ & 113 & 0,67 & ACEPIACION \\
\hline & Única & 85 & 1,4 & 1,17 & & & & \\
\hline Casa padre & Compartida & 30 & 2,2 & 0,783 & $-3,2$ & 113 & 0,001 & RECHAZO \\
\hline
\end{tabular}

*El estadístico utilizado es t de Student para la comparación de medias de la variable dicotómica tipo de custodia y las variables índices. La columna Gl señala los grados de libertad. El nivel de significación se representa con el estadístico $\delta$ y representa la probabilidad de cometer un error si rechazamos la hipótesis nula. Es decir, si la hipótesis nula es cierta. Si la probabilidad es pequeña (menor que o,05), diremos que existe asociación significativa entre ambas variables.

Fuente: elaboración propia a partir de los datos obtenidos en los juzgados de familia de Alicante, 2015-2017.

\section{Discusión}

En relación con el primer objetivo de esta investigación, relativo a la elaboración de un cuestionario que evalúe el arraigo familiar en casos de divorcio y realizar un análisis de sus características sociométricas, los resultados obtenidos ponen de manifiesto que el cuestionario de arraigo familiar (CAF) posee un adecuado nivel de consistencia interna. En lo que respecta a la validez del instrumento, el análisis de componentes principales llevado a cabo para examinar su dimensionalidad, mostró una estructura de tres factores. Además, parece que las puntuaciones obtenidas en el CAF correlacionan con la variable tipo de custodia. Los niveles de arraigo familiar que presentan los menores están más igualados en custodia compartida que en custodia única.

A partir de los datos obtenidos en el estudio, cabe concluir que el CAF cumple con los requisitos metodológicos para evaluar el arraigo familiar en casos de divorcio. El cuestionario ha sido construido con una finalidad práctica, tratando de responder a la necesidad que tienen los técnicos que evalúan la custodia compartida de contar con instrumentos de evaluación fácilmente administrables y específicos, adaptados a la edad de los menores, con buenas propiedades métricas y que estén adaptados a muestras españolas y validados en el terreno forense (Ramírez González, 2018; Arce et al., 2005).

En lo que concierne al segundo objetivo de la investigación, se procedió a realizar un análisis bivariable que mostrase la relación entre tipo de custodia y los tres componentes principales del cuestionario de arraigo familiar. Uno de los factores aglutina aquellas variables relacionadas con el entorno familiar del padre, el segundo factor reúne aquellos ítems vinculados al entorno familiar de la madre, y un tercer factor guarda relación con el papel jugado por terceras personas, en concreto otros miembros de las familias extensas y familias reconstituidas.

En relación con los dos primeros factores, el resultado parece lógico y esperable, ya que la calidad de la relación entre el padre y la madre y el menor representa un componente importante del capital social (Dufur et al., 2008). No es extraño que los menores valoren a sus padres y madres y a sus hogares siguiendo los mismos criterios. Sin embargo, en lo que concierne al tercer factor, los resultados del análisis muestran la importancia que adoptan la familia extensa y las familias reconstituidas en el proceso de divorcio de los progenitores. Este resultado vuelve a confirmarse cuando en el análisis 
bivariable lo relacionamos con la variable tipo de custodia y se advierte una relación positiva entre las variables custodia compartida y la presencia de la familia extensa y la familia reconstituida.

Este resultado es coherente con la literatura científica consultada, puesto que tras el divorcio, la red de parientes, especialmente, las abuelas y los abuelos contribuyen a sobrellevar las consecuencias económicas y afectivas de la separación. Así lo muestra, por ejemplo, la Encuesta de Salud, Envejecimiento y Jubilación en Europa (SHARE) cuando refleja que un $22,07 \%$ de los abuelos cuida de sus nietos (Badenes y López, 2011). Si comparamos con el resto de países de la Unión Europea, España es el país donde hay menos abuelos cuidadores. Sin embargo, los abuelos españoles que cuidan de sus nietos lo hacen con una intensidad mayor que los abuelos de otros países europeos.

Meil (2006) advertía que el papel de los abuelos y abuelas en la actualidad no era tanto el de sustituir a los padres en el cuidado de sus hijos e hijas, sino en todo caso el de ayudarles en caso de necesidad. Aunque los abuelos y abuelas juegan un papel muy importante en la conciliación de la vida familiar y la vida laboral de las nuevas generaciones, ellos no han pasado a asumir de forma generalizada el rol parental en el proceso de incorporación de las mujeres al mercado de trabajo. En un reciente estudio Meil (2014), advierte que en aquellas familias donde existe mayor coparentalidad, también aparece menor demanda de apoyo intergeneracional. Partiendo de la premisa de que en custodia compartida existe mayor grado de coparentalidad, los datos obtenidos en el estudio que se presenta parecen apuntar en la misma dirección que los resultados de Meil. El papel desempeñado por los abuelos y las abuelas es diferente en custodia compartida que en custodia única.

Nuestro estudio no ha profundizado sobre el papel que los abuelos y abuelas desempeñan en la vida de los nietos y nietas, pero pone de manifiesto su importancia en contextos de divorcio. Sería interesante, en futuras investigaciones, profundizar en el papel de los abuelos y abuelas en la formación de capital social en casos de divorcio. Al fin y al cabo, siguiendo a Coleman (1988) y Putnam (2000) las familias son una fuente de capital social, ya que implican conexiones entre individuos que a menudo ofrecen apoyo instrumental, informativo y emocional.

En lo que concierne a las familias reconstituidas, su situación es diferente, ya que no abundan los estudios sobre ellas en España (Ajenjo, 2016; Rivas, 2008). Las razones de esta escasez de estudios son diversas. Por una parte, la limitación de las fuentes estadísticas disponibles y, por otra, la pluralidad de perfiles sociodemográficos (Rivas Rivas, 2008, Avilés y Pérez-Pérez, 2014). Tampoco abundan en los estudios relacionados con el papel que juegan estas familias en las relaciones familiares después del divorcio (Treviño y Gumà, 2013).
Los resultados en la investigación que se presenta constatan la importancia que desempeñan las familias reconstituidas en los hijos de parejas divorciadas. Se puede advertir que, junto al papel desempeñado por las familias extensas, conforman uno de los factores extraídos en el análisis factorial que aglutina variables relevantes en la escala. Por otra parte, en el análisis bivariable se observa la relación entre las variables tipo de custodia y familia reconstituida. Se observa, además, que en las familias con custodia compartida los miembros de las familias reconstituidas están mejor valorados por los menores que en divorcios con custodia única.

Estos datos parecen apuntar a la tesis de Martín y Le Gall (1993), quienes mostraron la existencia de dos lógicas diferentes en la recomposición familiar: la lógica de sustitución y la lógica de continuidad. En la lógica de sustitución, la figura del padrastro o madrastra sustituye a la del progenitor que no tiene la custodia. En la lógica de la continuidad, ambas figuras padre-padrastro o madre-madrastra se suman, no se sustituyen. La lógica de la sustitución se basa en una imagen tradicional de la familia. La lógica de la continuidad se basa en una negociación permanente entre los excónyuges y los nuevos cónyuges. La convivencia con la nueva pareja del padre o de la madre favorece la construcción de un nuevo rol y un nuevo vínculo. La lógica de continuidad estaría más próximo a aquellas familias que desarrollan una forma de capital social puente (Putnam, 2000) y también a un modelo de familia negociadora, caracterizada por un reparto equitativo de las tareas y una implicación mutua en la atención a los hijos y un manejo de los conflictos de modo negociado (Meil, 2003).

Los resultados de esta investigación muestran diferencias entre las familias en custodia compartida y custodia única, pero no llegan a verificar las tesis propuestas por Meil (2006) respecto a la familia negociadora, ni las tesis de Martín y Le Gall (1993) en relación con la lógica de sustitución. Sin embargo, podrían alentar nuevos estudios que profundizasen en el papel desempeñado por las familias reconstituidas y su relación con el divorcio. Al fin y al cabo estas familias son el exponente de una nueva realidad social, en proceso continuo de experimentación y construcción (Rivas Rivas, 2008).

Por otra parte, el estudio se ha centrado en la relación entre dos variables: arraigo familiar y custodia compartida. Podría ser interesante iniciar posteriores investigaciones incorporando más variables al modelo, ya que en el estudio de la custodia compartida es necesario tener en cuenta una serie de factores para su evaluación conjunta (Viñes, 2012; Arch, 2008). El arraigo familiar es un factor valorado por el tribunal, pero no es condición suficiente en la atribución de la custodia compartida: la evaluación de la custodia compartida exige de un cúmulo de factores que deben ser evaluados. El arraigo familiar es tan solo uno de ellos. 
AEBY, G.; WIDMER, E. y DE CARLO, I. (2014): “Bonding and bridging social capital in step-and first-time families and the issue of family boundaries", Interpersona, vol. 8, n. 1 , págs. 1-51 [khttps:// doi.org/10.5964/ijpr.v8i1.149>].

AJENJO-COSP, M. y GARCÍA-SALADRIGAS, N. (2016): “Las parejas reconstituidas en España: un fenómeno emergente con perfiles heterogéneos", Revista Española de Investigaciones Sociológicas, vol. 155, n. ${ }^{-}$3, págs. 3-20 [〈https://reis.cis.es〉].

ALASCIO, L. T. (2011): "La excepcionalidad de la custodia compartida impuesta (art. 92.8 CC). A propósito de la sentencia del Tribunal Supremo de 1 de octubre de 2010", Indret. Revista para el análisis del Derecho, n.ำ 2, págs. 1-25 [<https://.www.raco.cat/index.php/InDret/ article/download/241329/323920>].

ARCE, R.; FARIÑA, F. y SEIJO, D. (2005): "Razonamientos judiciales en procesos de separación", Psicothema, vol. 1:7, n. ${ }^{\circ}$, págs. 57-63 [〈https://psicothema.com〉].

ARCH, M.; JARNE, A. y MOLINA, A. (2008): "Criterios de decisión para las recomendaciones de guarda y custodia de los niños", en RODRÍGUEZ, F.J.; BRINGAS, C.; FARIÑA, F.; ARCE, R.; y BERNARDO, A.: Psicología Jurídica, Familia y Victimología, Colección Psicología y Ley, no 6, Ediciones de la Universidad de Oviedo, págs. 105-114 [khttp:// gip.uniovi.es/T6EJD.pdf〉]

AVILÉS, M. y PÉREZ-PÉREZ, C. (2014): "Cuando los hijos viven con el padre. Estudio sociológico sobre las familias de padres custodios", Documentos de Trabajo de Sociología Aplicada, n. ${ }^{3}$, págs. 1-20 [<https://revistas.um.es/dtsa/article/ view/182021/159991)].

BAUMAN, Z. (2012): Amor líquido: Acerca de la fragilidad de los vínculos humanos, Argentina, Fondo de Cultura Económica.
- (2015): Modernidad líquida, Argentina, Fondo de Cultura Económica.

BECK, U. y BECK-GERNSHEIM, E. (2003): La individualización: El individualismo institucionalizado y sus consecuencias sociales y políticas, Barcelona, Paidós Ibérica.

BURT, R. (2004): "Structural holes and good ideas", American Journal of Sociology, vol. 110, n.으 2, págs. 349-399 [<https://doi. org/10.1086/421787>].

CASTELLS, M. (2003): El poder de la identitad, Barcelona, Editorial UOC.

- (2006): La sociedad red: una visión global, Madrid, Alianza Editorial.

CEA D'ANCONA, A. (1999): Metodología cuantitativa: estrategias y técnicas de investigación social, Madrid, Síntesis.

- (2007): La deriva del cambio familiar, Hacia formas de convivencia más abiertas y democráticas, Madrid, Centro de Investigaciones Sociológicas.

COLEMAN, J.S. (1988): "Social capital and schools". The Education Digest, vol. 53, n. 8, págs. 1-6.

DUFUR, M. J.; PARCEL, T.L. y MCKUNE, B.A. (2008): “Capital and context: Using social capital at home and at school to predict child social adjustment", Journal of Health and Social Behavior, vol. 49, n.ำ 2, págs. 146-161.

FARIÑA, F.; ARCE, R. y SOTELO, A. (2010): “¿Es efectivo el estudio psicométrico estándar del peritaje del estado clínico y de la disimulación en progenitores en litigio por la guarda y custodia de menores?", Revista lberoamericana de Psicología y Salud, vol. 1, n.․1, págs. 51-65. [hhttps://www.usc.es/suips〉]. 
FURSTENBERG F.F. y HUGHES, M.E. (1995): "Social capital and successful development among at-risk youth", Journal of Marriage and the Family, vol. 67 , n. ${ }^{4}$, págs. 809-821.

GRANOVETTER, M. (1973): «The strength of weak ties», American Journal of Sociology, vol. 78, no 6, págs. 1360-1380. [khttps://doi. org/10.1086/225469>].

GÓMEZ, F. y SOTO R. (2015): “El trabajador social de la Administración de Justicia española en los procesos de rupturas matrimoniales", Estudios Socio-Jurídicos, vol. 17, n.ํㅗ 1, págs. 197-232 [khttp://dx.doi.org/10.12804/ esj17.02.2015.06>].

WIDMER, E.; GAËLLE, A. y SAPIN, M. (2013): “Collecting family network data", International review of Sociology, vol.23, no 1 , págs. 27-46 [http://DOI: 10.1080/03906701.2013.771049].

IBAÑEZ-VALVERDE, V. (2004): "El laberinto de la custodia compartida. Claroscuros de un solo nombre con varios significados", Boletín De Derecho De Familia, vol. 4, nํ40-41, págs. 1-15 [https:// www.researchgate.net/.../280726891].

JURADO, T. (2008): “Las nuevas familias españolas”, en GONZÁLEZ JUAN JESÚS Y REQUENA MIGUEL (eds.), Tres Décadas de cambio social en España, Madrid, Alianza, págs. 259-292.

MARURI, R. y LAO, J. (2013): “De la monoparentalitad a la reconstitución familiar: Un análisis a partir de las fuentes transversales". Revista de Sociología, vol. 98, n.ำ 2, págs. 287-309 [rhttps://www.raco.cat/index.php/Papers/ article/view/263706)].

MARTIN, C. y LE GALL, D. (1993): “Transitions familiales, logiques de recomposition et modes de régulation conjugale", en MEULDERS, M.T. y THÉRY, I. (Eds.): Les recompositions familiales aujourd'hui, págs.137-158.

MEIL, G.; y ROGERO-GARCÍA, J. (2014): “Abuelas, abuelos y padres varones en el cuidado de la infancia", Cuadernos de Relaciones Laborales, vol. 32, n. 1, págs. 49-67 [rhttps://revistas.ucm.es/index. $\mathrm{php} /$ CRLA/article/view/44713'].

MEIL, G. (2006): Padres e hijos en la España actual. Barcelona, Fundación La Caixa.

BADENES, P. y LÓPEZ-LÓPEZ, M.T. (2011): “Doble dependencia: Abuelos que cuidan nietos en España”, Zerbitzuan: Gizarte Zerbitzuetarako Aldizkaria, Revista De Servicios Sociales, vol. 49, n.ำ 1, págs. 107-125 [<https://www. zerbitzuan.net/documentos/zerbitzuan/ Doble\%2odependencia.pdf $>$ ].

PUTNAM, R. (2000): Bowling alone. The collapse and revival of civic America, New York, Simon \& Schuster.

RAMÍREZ-PLASCENCIA, J. y HERNÁNDEZ-GONZÁLEZ, E. (2012): “¿Tenía razón Coleman? Acerca de la relación entre capital social y logro educativo". Sinéctica, vol. 39, n. ${ }^{-1}$, págs. 01-14 [<https:// versión On-line ISSN 2007-7033versión impresa ISSN 1665-109X>].

RAMÍREZ-GONZÁLEZ, M. (2003): Cuando los padres se separan: alternativas de custodia para los hijos (guía práctica), Madrid, Biblioteca Nueva.

- (2017): Las custodias infantiles. Una mirada actual. Madrid, Biblioteca Nueva.

RIVAS, A. (2008): "Las nuevas formas de vivir en familia: el caso de las familias reconstituidas", Cuadernos de Relaciones Laborales, vol. 26, n.ำ 1, págs. 179-202 [«http://file:///C:/Users/Asus/ Downloads/33417-33433-1-PB\%20(1).PDF].

RODRÍGUEZ-DOMÍNGUEZ, C.; JARNE, A.; CARBONELL, $X$. (2015): "Análisis de las atribuciones de guarda y custodia de menores en las sentencias judiciales, Acción Psicológica, vol. 12, n.음 1, págs. 1-10 [rhttps://doi.org/10.5944/ ap.12.1.13383〉].

RUIZ-CALLADO, R., y ALCÁZAR, R. (2017): “Factores determinantes en la atribución de la custodia compartida. Un estudio sociológico en los juzgados de familia", en BECERRIL, D. y VENEGAS, M., La custodia compartida en España, Madrid, Dykinson, págs. 109-125.

RUIZ-RODRIGUEZ, P. (2013): El trabajador social forense en los tribunales españoles. Málaga, Colegio Oficial de Diplomados y Diplomadas en Trabajo Social y AA. SS. de Málaga.

SAPOSNEK, D. (1991): "The value of children in mediation: A cross-cultural perspective". Conflict Resolution Quarterly, vol. 8, n.ํㅜ 4, págs. 325-342. [〈https://doi.org/10.1002/crq.3890080408>].

SIMÓN, M. (2009): “Aportaciones del trabajo social a la pericial de familia", Cuadernos de derecho

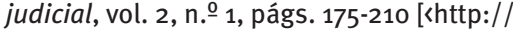
bscw.rediris.es/.../Aportaciones $\% 20$ del $\% 20$ Trabajo\%20Social\%20a\%2ola\%2oPericial

SOLSONA, M.; SPIJKER, J. y AJENJO, M. (2017): "Calidoscopio de la custodia compartida", en: BECERRIL, D. y VENEGAS, M., La custodia compartida en España, Madrid, Dykinson, págs. 45-54.

SUSO, A.; GONZÁLEZ DE CHÁVEZ, I.; PÉREZ, A. y VELASCO, M. (2007): Análisis de los modelos de custodia derivado de situación de separación y divorcio en España. Madrid, Instituto de la Mujer [rhttp://www.inmujer.gob.es/areasTematicas/ estudios/estudioslinea2013/docs/ AnalisisModelosCustodia.pdf〉].

TREVIÑO, R. y GUMÀ J. (2013): “De la monoparentalidad a la reconstitución familiar: un análisis a partir de fuentes transversales", Revista de Sociología, vol. 98, n. ${ }^{\circ}$ 2, págs. 287-309. [<http://dx.doi. org/10.5565/rev/papers/v98n2.357>].

VIÑES, D. (2012): “Medidas relativas a los hijos menores en caso de ruptura. Especial referencia a la guarda" Revista para el análisis del Derecho, vol. 3, n. ${ }^{-1}$, págs. 9-55 [<https://dialnet. unirioja.es/ejemplar/30993〉]. 


\section{Anexo \\ Cuestionario arraigo sociofamiliar para menores en supuesto de custodia compartida disputada}

\section{Datos sociodemográficos del menor}

1. Indique con número la edad del menor

\begin{tabular}{|l|l|l|}
\hline 1 & Edad & \\
\hline
\end{tabular}

2. Indique con una $x$ el sexo y tipo de custodia del menor

\begin{tabular}{|c|l|l|}
\hline 2 & Sexo & \\
\hline 1 & Varón & \\
\hline 2 & Mujer & \\
\hline
\end{tabular}

\begin{tabular}{|c|l|l|}
\hline 3 & Tipo de custodia & \\
\hline 1 & Custodia compartida & \\
\hline 2 & Custodia materna & \\
\hline 3 & Custodia paterna & \\
\hline 4 & Otras & \\
\hline
\end{tabular}

\section{Dimensión clima familiar general}

En este apartado se le pregunta la menor si le gusta y cómo se siente en el entorno familiar de su padre y de su madre. Se trata de que valoren en una escala: Nunca, A veces, Muchas veces, Siempre.

\section{La casa de mi madre}

\begin{tabular}{|c|c|c|c|c|c|}
\hline 4 & Casa de mi madre & Nunca & A veces & $\begin{array}{c}\text { Muchas } \\
\text { veces }\end{array}$ & Siempre \\
\hline 1 & Me gusta estar en esta casa & & & & \\
\hline 2 & Aquí tengo mi propia habitación y mis cosas & & & & \\
\hline 3 & Se come bien en esta casa & & & & \\
\hline 4 & Tengo amigos en el barrio & & & & \\
\hline 5 & Me siento bien en esta casa & & & & \\
\hline
\end{tabular}

\section{La casa de mi padre}

\begin{tabular}{|c|c|c|c|c|c|}
\hline 5 & Casa de mi padre & Nunca & A veces & $\begin{array}{c}\text { Muchas } \\
\text { veces }\end{array}$ & Siempre \\
\hline 1 & Me gusta estar en esta casa & & & & \\
\hline 2 & Aquí tengo mi propia habitación y mis cosas & & & & \\
\hline 3 & Se come bien en esta casa & & & & \\
\hline 4 & Tengo amigos en el barrio & & & & \\
\hline 5 & Me siento bien en esta casa & & & & \\
\hline
\end{tabular}

\section{Dimensión arraigo familiar}

En este apartado se le pregunta al entrevistado por el nombre y parentesco de sus familiares más próximos, así como por la frecuencia con la que dispone de su ayuda cuando lo necesita. Se trata de que valore en una escala: nunca, a veces, muchas veces, siempre, a cada uno de los miembros de forman parte de su entorno familiar más próximo. 
Familia de origen y familia reconstituida

\begin{tabular}{|c|l|l|l|l|l|}
\hline \multicolumn{2}{|c|}{ Familia extensa } & Nunca & A veces & Muchas veces & Siempre \\
\hline 6 & & & & & \\
\hline 1 & Padre & & & & \\
\hline 2 & Madre & & & & \\
\hline 3 & Abuelo paterno & & & & \\
\hline 4 & Abuela paterna & & & & \\
\hline 5 & Abuelo materno & & & & \\
\hline 6 & Abuela materna & & & & \\
\hline 7 & Tíos/tías paternos & & & & \\
\hline 8 & Tíos/tías maternos & & & & \\
\hline 9 & Primos/as paternos/as & & & & \\
\hline 10 & Primos/as maternos/as & & & & \\
\hline 11 & Otros & & & & \\
\hline
\end{tabular}

\begin{tabular}{|c|l|l|l|l|c|}
\hline \multicolumn{7}{|c|}{ Hermanos/as casa padre } & Nunca & A veces & Muchas veces & Siempre \\
\hline $\mathbf{9}$ & & & & & \\
\hline 1 & Hermano/a 1 & & & & \\
\hline 2 & Hermano/a 2 & & & & \\
\hline 3 & Hermano/a 3 & & & \\
\hline
\end{tabular}

\begin{tabular}{|c|l|l|l|c|c|}
\hline \multicolumn{7}{|c|}{ Hermanos/as casa madre } & Nunca & A veces & Muchas veces & Siempre \\
\hline 10 & & & & & \\
\hline 1 & Hermano/a 1 & & & & \\
\hline 2 & Hermano/a 2 & & & & \\
\hline 3 & Hermano/a 3 & & & \\
\hline
\end{tabular}

\begin{tabular}{|c|l|c|c|c|c|}
\hline \multicolumn{9}{|c|}{ Familia reconstituida } & Nunca & A veces & Muchas veces & Siempre \\
\hline $\mathbf{1 1}$ & & & & & \\
\hline 1 & Pareja padre & & & & \\
\hline 2 & Pareja madre & & & & \\
\hline 3 & Otros (especificar) & & & & \\
\hline
\end{tabular}

